\title{
FUNDAMENTOS E EVOLUÇÃO DA LIMITAÇÃO CONSTITUCIONAL DA DURAÇÃO DO TEMPO DE TRABALHO NO BRASIL
}

\section{Rodrigo Coimbra}

Doutor em Direito pela Pontifícia Universidade Católica do Rio Grande do Sul, Porto Alegre/ RS. Mestre em Direito pela Universidade Federal do Rio Grande do Sul, Porto Alegre/RS. Professor Adjunto de Direito do Trabalho e Processo do Trabalho da Universidade Federal do Rio Grande do Sul, Porto Alegre/RS. Advogado. E-mail: <rodrigo.coimbra@terra.com.br>.

Resumo: O presente artigo trata sobre um dos mais importantes temas do direito do trabalho, desde sua formação histórica até sua inclusão nas Constituições brasileiras: a limitação da duração do tempo de trabalho (diária, semanal, mensal e anual). Os problemas investigados na pesquisa são os seguintes: os fundamentos e os limites jurídicos da duração do tempo de trabalho no Brasil continuam necessários e adequados? Sustenta-se que os fundamentos jurídicos da duração do tempo de trabalho no Brasil continuam adequados e inspiram limites necessários, motivados pelos aspectos de natureza física ou biológica, psíquica e psicológica, social e cultural, bem como econômica, cujos limites maiores, em última análise, são a vida, a saúde e a dignidade da pessoa humana dos trabalhadores. Como metodologia científica de abordagem do assunto, será utilizado o método dedutivo, e a abordagem da pesquisa se dará pelo modelo qualitativo.

Palavras-chave: Duração de trabalho. Evolução histórica. Fundamentos. Direitos fundamentais. Direitos humanos.

Sumário: 1 Introdução - 2 Fundamentos da duração do tempo de trabalho - 3 Evolução histórica dos limites do tempo de trabalho - 4 Considerações Finais - Referências

\section{Introdução}

O presente artigo trata do tema da duração do tempo de trabalho e, delimitadamente, dos fundamentos e da evolução das limitações constitucionais da duração do tempo de trabalho.

A duração de trabalho é um dos temas mais importantes do direito do trabalho, tendo assumido posição de destaque no desenvolver de toda a evolução histórica desse ramo do direito em conjunto com o tema salário. ${ }^{1}$

1 DELGADO, Maurício Godinho. Curso de Direito do Trabalho. 10. ed. São Paulo: Ltr, 2011, p. 805. Conforme Délio Maranhão, o salário é preço atribuído à força de trabalho alienada, e a jornada é a medida dessa 
A pesquisa insere-se no âmbito das limitações constitucionais ao exercício da atividade econômica, como manifesta intervenção do Estado na economia e nas relações de trabalho, por meio de limites mínimos e máximos estabelecidos pela legislação. Abrange a jornada de trabalho máxima, o descanso semanal remunerado, os intervalos intra e interjornada e o descanso anual remunerado.

Os problemas levantados para investigação são: os fundamentos e os limites jurídicos da duração do tempo de trabalho no Brasil continuam necessários e adequados?

O trabalho está dividido em seu desenvolvimento em duas partes. Na primeira, analisam-se os fundamentos da duração do tempo de trabalho e, na segunda, resgata-se a evolução histórica dos limites do tempo de trabalho no direito internacional (com foco nos principais países da Europa e nas convenções da Organização Internacional do Trabalho) e no direito do trabalho brasileiro.

Como método científico de abordagem do assunto, será utilizado o dedutivo, aquele cujo antecedente é constituído de princípios universais, plenamente inteligiveis, do qual se chega a um consequente menos universal, inferir e concluir ao final. A abordagem da pesquisa se dará pelo modelo qualitativo na medida em que se buscará o entendimento do fenômeno em seu próprio contexto.

\section{Fundamentos da duração do tempo de trabalho}

O tempo tem grande relevância para o direito, pois, ainda que não seja um fato jurídico, por ser de outra dimensão, o seu transcurso integra, com muita frequência, suportes fáticos, como ocorre com a duração do trabalho. Quando previsto expressamente pela norma, o tempo é considerado elemento de suficiência para a configuração do fato jurídico respectivo. ${ }^{2}$

força que se aliena (MARANHÃO, Délio. Direito do Trabalho. 14. ed. Rio de Janeiro: Fundação Getúlio Vargas, 1987, p. 83). Delgado, salientando a inter-relação entre duração do trabalho e salário, esclarece que "não há regra jurídica ampliadora ou redutora da jornada que não tenha influência automática no montante salarial relativo devido ao empregado" (DELGADO, Maurício Godinho. Curso de Direito do Trabalho. 10. ed. São Paulo: Ltr, 2011, p. 806).

2 MELLO, Marcos Bernardes de. Teoria do fato jurídico: plano da existência. 8. ed. São Paulo: Saraiva, 1998, p. 44; TUCCI, José Rogério Cruz e. Tempo e processo: uma análise empírica das repercussões no tempo na fenomenologia processual (civil e penal). São Paulo: Revista dos Tribunais, 1997, p. 57. 
A energia despendida e alienada pelo trabalhador subordinado é limitada e precisa ser renovada por meio de repousos regulares ${ }^{3}$ como forma de restabelecer e manter sua energia física e mental e se relacionar com a família e a comunidade.

Após dizer que a matéria abrange o horário de trabalho, os repousos, as férias, a higiene e segurança do trabalho, D'Eufemia ${ }^{4}$ adverte que tais institutos são postos como limites ao poder diretivo do empregador e da autonomia contratual das partes.

De acordo com Pontes de Miranda, “o repouso de cada dia, esse, por sua essencialidade, acompanha o homem, como aos outros animais, através de toda a história da vida". ${ }^{5}$ Aduz Nascimento ${ }^{6}$ que o descanso é correlato ao trabalho: "Até no trabalho caseiro é assim. Trabalha-se e descansa-se".

Tratando dos fundamentos da necessidade de limitação da duração do trabaIho, D'Eufemia7 fala em "numerosos e variados motivos", destacando as razões humanas, sociais e econômicas em face dos limites fisiológicos do ser humano, bem como questões sociais, políticas e religiosas, de forma a poder participar da vida da comunidade. Acarreta maior rendimento e qualidade na execução do trabalho.

Como toda matéria que envolve classificação, não há unanimidade quanto aos tipos e a terminologia, mas, com menor ou maior amplitude, em geral a doutrina $^{8}$ não foge de considerar os aspectos de natureza:

(i) Física ou biológica - o trabalho em jornadas de elevada duração pode causar fadiga somática do trabalhador.

Gomes e Gottschalk ${ }^{9}$ esclarecem que o processo de fadiga se instala insidiosamente no organismo humano, conduzindo, quando crônica, à invalidez e velhice, abreviando a vida humana.

3 Os períodos de descanso ou de repouso, conforme Maurício Godinho Delgado, conceituam-se como: “Lapsos temporais regulares, remunerados ou não, situados intra ou intermódulos diários semanais ou anuais do período de labor, em que o empregado pode sustar a prestação de serviços e sua disponibilidade perante o empregador, com o objetivo de recuperação e implementação de suas energias ou de sua inserção familiar, comunitária e política" (DELGADO, Maurício Godinho. Curso de Direito do Trabalho. 5. ed. São Paulo: Ltr, 2006, p. 917).

4 D'EUFEMIA, Giuseppe. Diritto del lavoro. Napoli: Morano, 1969, p. 185-186.

5 PONTES DE MIRANDA, Francisco Cavalcanti. Tratado de Direito Privado. t. 47. Campinas: Bookseller, 2006, p. 220.

6 NASCIMENTO, Amauri Mascaro. Direito contemporâneo do trabalho. São Paulo: Ltr, 2011, p. 481.

7 D’EUFEMIA, Giuseppe. Diritto del lavoro. Napoli: Morano, 1969, p. 187.

8 Utiliza-se aqui de uma mescla dos critérios utilizados por SUSSEKIND, Arnaldo et al. Instituições de Direito do Trabalho. v. 2. 20. ed. São Paulo: Ltr, 2002, p. 785 e GARCIA, Gustavo Filipe Barbosa. Manual de Direito do Trabalho. 5. ed. São Paulo: Método, 2012, p. 509-510.

9 GOMES, Orlando; GOTTSCHALK, Élson. Curso de Direito do Trabalho. 18. ed. Rio de Janeiro: Forense, 2007, p. 295. 
Jorge Luiz Souto Maior ${ }^{10}$ defende o direito à desconexão do trabalho e adverte que os altos empregados estão sujeitos a jornadas de trabalho extremamente elevadas, interferindo negativamente na sua vida, minando sua saúde e desagregando sua família.

(ii) Psíquica e psicológica - os efeitos nefastos do lavor com jornadas extenuantes podem gerar não apenas a fadiga muscular ou física, mas também o esgotamento psíquico e psicológico do empregado.

Tal espécie de fadiga afeta a saúde mental e a capacidade de concentração do empregado, podendo até mesmo gerar, conforme destaca Gustavo Filipe Barbosa Garcia, ${ }^{11}$ "doenças ocupacionais de ordem psíquica, como a chamada síndrome do esgotamento profissional” (Síndrome de Burnout).

Vale lembrar que a saúde (física e mental) é um direito fundamental do trabalhador. Conforme destaca Franscisco Rossal de Araújo: ${ }^{12}$

\begin{abstract}
Inserir a saúde do trabalhador como direito fundamental é fruto de uma longa luta e ampliação de consciência que pode ser vista na evolução normativa. O certo é que esse direito está dentro do catálogo de direitos e liberdades positivadas que compõe o conjunto de direitos fundamentais na Constituição Brasileira, tanto no que diz respeito à vida e à integridade física - quanto ao seu aspecto social: o direito à saúde e a ao meio ambiente de trabalho sadio.
\end{abstract}

Nessa linha, Alice Monteiro de Barros ${ }^{13}$ chama atenção para os efeitos mais recentemente salientados do estresse enquanto fato gerador das longas jornadas de trabalho.

Nesse contexto, Maurício Godinho Delgado destaca que a modulação da duração do trabalho é parte integrante de qualquer política de saúde pública, uma vez que influencia, exponencialmente, a eficácia das medidas de medicina e segurança do trabalho adotadas na empresa. ${ }^{14}$

(iii) Social e cultural - é necessário também para a sociedade que a pessoa, além de trabalhar, exerça outras atividades junto à comunidade em que vive e à sua família, base da sociedade.

10 MAIOR, Jorge Luiz. Do direito à desconexão do trabalho. Justiça do Trabalho, Porto Alegre: Hs Editora, $\mathrm{n}$. 238, out. 2003, p. 7-22.

11 GARCIA, Gustavo Filipe Barbosa. Manual de Direito do Trabalho. 5. ed. São Paulo: Método, 2012, p. 506.

12 ARAÚJO, Francisco Rossal de. A saúde do trabalhador como direito fundamental (no Brasil). Justiça do Trabalho, Porto Alegre: Hs Editora, n. 317, p. 7-32 (em especial p. 14), maio 2010.

13 BARROS, Alice Monteiro de. Curso de Direito do Trabalho. 4. ed. São Paulo: Ltr, 2008, p. 655.

14 DELGADO, Maurício Godinho. Curso de Direito do Trabalho. 10. ed. São Paulo: Ltr, 2011, p. 807. Garcia classifica essa natureza como "humana" e a trata de maneira distinta das demais (GARCIA, Gustavo Filipe Barbosa. Manual de Direito do Trabalho. 5. ed. São Paulo: Método, 2012, p. 507). 
Arnaldo Sussekind ${ }^{15}$ destaca a importância de que os empregados tenham tempo disponível para atividades recreativas, culturais e físicas. Mário De La Cueva $^{16}$ acrescenta a importância da natureza cultural dos descansos.

Sublinhe-se que as normas que preveem os repousos regulares visam à promoção da saúde pública, não podendo, em regra, serem afastadas pela vontade privada (são normas imperativas, em regra geral), ${ }^{17}$ possuindo nítida função protetiva do trabalhador.

(iv) Econômica - por um lado, ao descansar de maneira adequada, o trabalho é desempenhado com maior qualidade e rendimento. ${ }^{18}$ Por outro lado, a fadiga física, psíquica e psicológica aumenta o risco de acidentes de trabalho e de doenças resultantes do trabalho, colocando a saúde, a segurança e a vida do trabalhador em risco, aumentando os riscos da infortunística do trabalho e dos custos a título de reparação dos danos decorrentes de acidentes do trabalho e doenças ocupacionais. ${ }^{19}$

Note-se que os repousos se constituem medidas muito importantes no contexto da moderna segurança e medicina laboral. Não obstante, a condição de trabalhador, dentro das condições específicas da prestação de trabalho, enseja um tratamento jurídico especial, mais detalhado do que a proteção jurídica dada a qualquer cidadão.

Proteger a vida, saúde e dignidade são ideais perseguidos de um modo geral para toda a cidadania; contudo, adquirem um matiz especial no tocante ao trabalho, em função das condições de risco em que se encontram determinadas atividades laborais. Por essa razão, o tema da saúde do trabalhador foi elevado ao nível constitucional no Brasil, ${ }^{20}$ tanto no que diz respeito às proteções aos riscos inerentes ao trabalho quanto no que tange à seguridade social e às indenizações decorrentes de acidentes de trabalho e doenças profissionais. ${ }^{21}$

Note-se que, por trás disso tudo, está o princípio da proteção do empregado - principal princípio do direito do trabalho -, que protege o sujeito empregado em detrimento do sujeito empregador como forma de compensar juridicamente o desequilíbrio econômico existente entre eles. Essa compensação ou nivelamento

15 SUSSEKIND, Arnaldo et al. Instituições de Direito do Trabalho. v. 2. 20. ed. São Paulo: Ltr, 2002, p. 785.

16 DE LA CUEVA, Mario. El nuevo Derecho Mexicano del Trabajo. t. 1. 19. ed. México: Porrúa, 2003, p. 272.

17 DE LA CUEVA, Mario. El nuevo Derecho Mexicano del Trabajo. t. 1. 19. ed. México: Porrúa, 2003, p. 276. Nesse sentido também, D’EUFEMIA, Giuseppe. Diritto del lavoro. Napoli: Morano, 1969, p. 186; DELGADO, Maurício Godinho. Curso de Direito do Trabalho. 5. ed. São Paulo: Ltr, 2006, p. 917.

18 D'EUFEMIA, Giuseppe. Diritto del lavoro. Napoli: Morano, 1969, p. 187.

19 GARCIA, Gustavo Filipe Barbosa. Manual de Direito do Trabalho. 5. ed. São Paulo: Método, 2012, p. 506.

20 ARAÚJO, Francisco Rossal de. A saúde do trabalhador como direito fundamental (no Brasil). Justiça do Trabalho, n. 317, p. 7-32 (em especial p. 7), maio 2010.

21 Constituição Federal, art. 7으, incisos XXII e XXVIII. 
jurídico se dá por meio de normas imperativas ou cogentes que restringem a autonomia da vontade dos sujeitos, estabelecendo limites jurídicos mínimos e máximos que precisam ser necessariamente observados pelos contratos individuais de trabalho, pelas normas coletivas de trabalho e pelas demais fontes formais de direito do trabalho. ${ }^{22}$

O princípio da proteção do trabalhador, por sua vez, está intimamente ligado com o princípio da dignidade da pessoa humana, "princípio maior do direito constitucional contemporâneo, espraiando-se, com grande intensidade, no que tange à valorização do trabalho", nas palavras de Delgado. ${ }^{23}$

Nesse contexto, os direitos sociais dos trabalhadores são direitos fundamentais constitucionalmente assegurados e direitos humanos pelo seu forte vínculo (pelo menos em boa parte dos casos) com a dignidade da pessoa humana e o correlato direito (e garantia) a um mínimo existencial, possuindo titularidade individual e coletiva (assim como difusa) em relação de coexistência e complementariedade. ${ }^{24}$

\section{Evolução histórica dos limites do tempo de trabalho}

\subsection{No direito internacional}

As fontes materiais da necessidade de limitação jurídica do tempo de trabaIho afloraram na Revolução Industrial, que foi a "fermentação" que daria origem ao surgimento do direito do trabalho, na marcante expressão de Segadas Viana. ${ }^{25}$

$\mathrm{O}$ direito do trabalho propriamente dito, incluindo as matérias de jornada de trabalho, descanso semanal remunerado, intervalos e férias, só começa a acontecer após a Revolução Francesa (1789), durante o século XIX. ${ }^{26}$

22 COIMBRA, Rodrigo; ARAúJO, Francisco Rossal de. Direito do Trabalho I. São Paulo: Ltr, 2014, p. 140. O princípio da proteção do empregado é um "imperativo de igualdade material" segundo Guilherme Guimarães Feliciano, que também destaca a "função geral de cariz constitucional (derivada, no Brasil, do art. 7ํㅡ, da CRFB), que é a de reequilibrar materialmente as posições jurídicas geralmente antagônicas nos conflitos laborais (empregado e empregador)", conforme FELICIANO, Guilherme Guimarães. Curso crítico de direito do trabalho: teoria geral do direito do trabalho. São Paulo: Saraiva, 2013, p. 245.

23 DELGADO, Maurício Godinho; DELGADO, Gabriela Neves. O princípio da dignidade da pessoa humana e o Direito do Trabalho. In: SARLET, Ingo Wolfgang; MELO FILHO, Luiz Philippe Vieira de; FRAZÃO, Ana de Oliveira (Coords.). Diálogos entre o Direito Trabalho e o Direito Constitucional: estudos em homenagem a Rosa Maria Weber. São Paulo: Saraiva, 2014, p. 208.

24 SARLET, Ingo Wolfgang. Direitos fundamentais e processo: o direito à proteção e promoção da saúde entre tutela individual e transindividual. Revista de Processo, São Paulo, v. 199, p. 13-39 (em especial p. 19), set. 2011.

25 VIANA, Segadas et al. Instituições de Direito do Trabalho. v. 1. 20. ed. São Paulo: Ltr, 2002, p. 41.

26 NASCIMENTO, Amauri Mascaro. Iniciação ao Direito do Trabalho. 24.ed. São Paulo: Ltr, 1998, p. 35. 
Somente no final do século XIX, surgiram as condições sociais que tornaram possivel o aparecimento desse ramo do direito, com características próprias e autonomia doutrinária. ${ }^{27}$ Os limites do tempo de trabalho, assim como o direito do trabalho como um todo, são produtos típicos da industrialização e do sistema capitalista destes últimos tempos. ${ }^{28}$

Esse contexto gerou significativas reações por parte dos trabalhadores, que, unidos em sindicatos, reivindicavam um direito que os protegesse minimamente, capaz de coibir os abusos do empregador e preservar a sua dignidade. Pressionaram os patrões a atenderem seus pleitos por meio de greves, por vezes travando choques violentos entre as massas e as forças policiais. ${ }^{29}$

Outro fato significativo no processo de formação ocorreu durante o período da segunda fase da Revolução Industrial: a publicação do Manifesto do Partido Comunista. Em 1848, Karl Marx e Friedrich Engels externaram ao mundo os protestos dos trabalhadores em relação às lutas sociais, paradas de trabalho, prisões, mortes e todo o tipo de desordens em voga na época, fazendo com que o Estado se voltasse para a nova realidade social, e reivindicaram condições mínimas de trabalho, dentre as quais, limitação da jornada de trabalho, descanso semanal remunerado e férias anuais remuneradas. ${ }^{30}$

Outro marco histórico importante na evolução histórica do direito do trabalho como um todo e da limitação do tempo de trabalho em particular é o posicionamento da Igreja Católica, por meio dos seus documentos denominados encíclicos, dentre os quais se destacam a Rerum Novarum (que significa "Coisas Novas"), do Papa Leão XIII, datada de 15 de maio de 1891, pela qual a igreja reconhecia a injustiça social da época, acabando por aceitar e recomendar a intervenção estatal na economia como único meio capaz de cobrar os abusos do regime. Essa encíclica exige toda uma legislação protetora dos empregados e manifesta preocupação expressa sobre a limitação do tempo de trabalho dizendo que "o número de horas

27 Para um estudo aprofundado das fontes do direito do trabalho, ver COIMBRA, Rodrigo; ARAÚJO, Francisco Rossal de. Equilíbrio instável das fontes formais do Direito do Trabalho. Justiça do Trabalho, v. 324, p. 4875, dez. 2010. Para o estudo da chamada questão social e suas teorias, ver BARBAGELATA, Héctor-Hugo. A evolução do pensamento do direito do trabalho. São Paulo: Ltr, 2012, em especial p. 15-45.

28 MORAES FILHO, Evaristo de; MORAES, Antônio Carlos Flores de. Introdução ao Direito do Trabalho. 7. ed. São Paulo: Ltr, 1995, p. 74.

29 SUSSEKIND, Arnaldo et al. Instituições de Direito do Trabalho. v. 1. 20. ed. São Paulo: Ltr, 2002, p. 42; CESARINO JÚNIOR, Antônio Ferreira; CARDONE, Marly Antonieta. Direito Social: teoria geral do direito social, direito contratual do trabalho, direito protecionista do trabalho. 2. ed. São Paulo: Ltr, 1993, p. 64. Desde então, com sentido revolucionário ou simplesmente reformista, não parou mais a reivindicação dos trabalhadores por melhores condições de vida. Destacam Hueck e Nipperdey a característica da "forte acentuação da ideia coletiva, o que permite falar, frequentemente, do direito coletivo do trabalho" (HUECK, A.; NIPPERDEY, H. C. Compendio de derecho del trabajo. Madrid: Revista de Direito Privado, 1963, p. 34).

30 MARX, Karl. Manifesto do Partido Comunista. Porto Alegre: L\&PM, 2001, p. 129-131. 
de trabalho diário não deve exceder a força dos trabalhadores" e que deveria haver um descanso semanal "no dia do Senhor". ${ }^{31}$

Do ponto de vista político, o modelo de Estado liberal clássico permitia a plena autonomia das partes, sem nenhuma intervenção do Estado nas relações de trabalho. Mário De La Cueva ${ }^{32}$ usa a expressão “a histórica controvérsia doutrinária sobre o princípio da jornada máxima”, referindo que os trabalhadores, antes da Revolução Industrial, tinham por hábito laborar do nascer ao pôr do sol.

Na maioria dos países da Europa, por volta de meados de 1800, a jornada de trabalho era de 12 a 16 horas, principalmente entre mulheres e menores. Nos Estados Unidos da América, no mesmo período, a jornada de trabalho estava balizada entre 11 e 13 horas. Na Inglaterra, em 1847, foi fixada a jornada em 10 horas; em Paris, 11 horas. Em 1868, nos Estados Unidos, a jornada foi determinada em 8 horas no serviço público federal, tudo conforme Sérgio Pinto Martins. ${ }^{33}$

$\mathrm{Na}$ América Latina, o Chile foi o primeiro a estabelecer o limite de 8 horas para os trabalhadores estatais (1908), seguido de Cuba, em 1909, para os mesmos empregados, e do Uruguai, em 1915. ${ }^{34}$ A partir de 1915 , foi se generalizando a jornada de oito horas na maioria dos países, após diversos movimentos dos trabalhadores, inclusive greves. ${ }^{35}$

No final da Primeira Guerra, tem-se uma nova era com o reconhecimento internacional do direito do trabalho. Antes da Primeira Guerra Mundial, o direito do trabalho estava constituído por um conjunto de direitos nacionais.

O acordo que pôs fim a I Guerra Mundial, o Tratado de Versalhes, foi celebrado no Palácio de Versalhes, em 1919, em Paris. Em seu art. 4ํㅜ , faz menção à "questão social" e não admite que o trabalho humano seja tratado como mercadoria. Entre outras disposições, assegura no que tange à duração de trabalho, jornada de oito horas e carga semanal de 48 horas, igualdade de salário para trabalho de igual valor, repouso semanal e inspeção do trabalho (art. 427). ${ }^{36}$

31 LEÃO XIII. Carta encíclica "Rerum Novarum" sobre a condição dos operários. Disponível em: <http:// www.vatican.va/holy_father/leo_xiii/encyclicals/documents/hf_l-xiii_enc_15051891_rerum-novarum_ po.html>. Acesso em: 10 abr. 2013. O repouso semanal é ligado à tradição religiosa. Esclarece Pontes de Miranda que "noutras religiões o domingo é o dia do Sol. Os israelitas fazem esse dia no sábado. Os cristãos atenderam a que foi no domingo que se deu a ressurreição. Daí a transferência (PONTES DE MIRANDA, Francisco Cavalcanti. Tratado de Direito Privado. t. 47. Campinas: Bookseller, 2006, p. 220).

32 DE LA CUEVA, Mario. El nuevo Derecho Mexicano del Trabajo. t. 1. 19. ed. México: Porrúa, 2003, p. 271-272.

33 MARTINS, Sérgio Pinto. Direito do Trabalho. 24. ed. São Paulo: Atlas, 2008, p. 477.

34 BARROS, Alice Monteiro de. Curso de Direito do Trabalho. 4. ed. São Paulo: Ltr, 2008, p. 654; MARTINS, Sérgio Pinto. Direito do Trabalho. 24. ed. São Paulo: Atlas, 2008, p. 477.

35 GARCIA, Gustavo Filipe Barbosa. Manual de Direito do Trabalho. 5. ed. São Paulo: Método, 2012, p. 506.

36 HEPLE, Bob. La formación del Derecho del Trabajo en Europa. Madrid: Ministerio de Trabajo y Seguridad Social, 1994, p. 339; OLEA, Manuel Alonso. Introdução ao Direito do Trabalho. 4. ed. São Paulo: Ltr, 1984, p. 231. O Tratado de Versalhes confere posição definitiva aos ordenamentos jurídicos nacionais e internacionais, sobretudo pela ação da Organização Internacional do Trabalho - OIT, também criada em 
Nesse contexto, a primeira Convenção da então recém-criada OIT, a Convenção ํo 1, de 1919, trata sobre duração de trabalho na indústria, estabelecendo o limite máximo de "oito horas por dia e 48 horas por semana".

Em sequência, diversas convenções sobre o tempo de trabalho foram adotadas, dentre as quais se destacam: a Convenção ํㅜ 30, de 1930, que estabelece a jornada de oito horas para os trabalhadores do comércio e dos escritórios; a Convenção no 31, que fixa em 7h45min a jornada dos trabalhadores das minas de carvão; a Convenção № 40, de 1935, que propõe a redução da carga semanal para 40 horas; a Convenção no 47, de 1935, que propõe a redução da carga semanal para 35 horas, num período em que o mundo se encontrava devastado pela crise econômica e pela guerra. ${ }^{37}$

O direito ao descanso mínimo semanal de um dia foi introduzido na Convenção do Descanso Semanal o 14, de 1921, limitado, inicialmente, aos trabalhadores da indústria.

A Convenção № 106, de 1957, promulgada pelo Brasil em 1966 (Decreto no 58.823/66), estendeu o descanso semanal remunerado aos trabalhadores do comércio e dos escritórios. ${ }^{38}$

A Convenção $n$ ํ132, revisa em 1970 a fixação das férias anuais remuneradas, de no mínimo três semanas (promulgada pelo Brasil somente em 1999 - Decreto no $3.197 / 1999) .{ }^{39}$

A matéria da duração do trabalho e todos os aspectos que a circundam sofrem influxos diretos e indiretos da globalização da economia. Os "processos de globalização" 40 são irreversíveis, tendo se caracterizado mais recentemente por um fenômeno multifacetado com dimensões econômicas, sociais, políticas, culturais e jurídicas interligadas de modo complexo, tendo gerado uma nova ordem econômica mundial e a consequente necessidade de reestruturação global e do papel do direito do trabalho nesse mundo planificado. ${ }^{41}$

1919, que desenvolveu um importante papel de universalização do direito do trabalho (BARROS, Alice Monteiro de. Curso de Direito do Trabalho. 4. ed. São Paulo: LTr, 2008, p. 62).

37 Conforme MARTINS, Sérgio Pinto. Convenções da OIT. São Paulo: Atlas, 2009, p. 223.

38 Conforme MARTINS, Sérgio Pinto. Convenções da OIT. São Paulo: Atlas, 2009, p. 223.

39 LEE, Sangheon. Duração do trabalho em todo o mundo: tendências de jornadas de trabalho, legislação e políticas numa perspectiva global comparada. Brasília: OIT, 2009, p. 1-2; D’EUFEMIA, Giuseppe. Diritto del lavoro. Napoli: Morano, 1969, p. 187-188.

40 Segundo a expressão cunhada por Boaventura de Souza Santos, que dá maior dinâmica a este fenômeno que segue em andamento nos dias atuais (SANTOS, Boaventura de Souza. Os processos de globalização. In: SANTOS, Boaventura de Souza (Org.). A globalização e as ciências sociais. 3. ed. São Paulo: Cortez, 2005, p. 25).

41 COIMBRA, Rodrigo. Globalização e internacionalização dos direitos fundamentais dos trabalhadores. Revista de Direito do Trabalho, São Paulo: Revista dos Tribunais, n. 146, p. 411-431 (em especial p. 426), abr./jun. 2012. 
A convergência e a democratização das tecnologias (rede mundial de computadores, computador pessoal - PC, pen drives, wireless) estão formando o que se chama de sociedade global ou sociedade da informação e evidenciam uma nova ordem econômica mundial, importante, complexa e inevitável. ${ }^{42}$ Trata-se de fenômeno ainda muito recente, atual e com reflexos importantes em termos de duração do trabalho.

As mudanças mais recentes no mundo do trabalho têm gerado o que Domenico de $\mathrm{Masi}^{43}$ chama de "desestruturação do tempo e do espaço de trabalho", que aparece em várias situações novas, dentre as quais se destaca o teletrabalho. ${ }^{44}$

Os temas envolvendo duração do trabalho se entrelaçam com a chamada flexisegurança ${ }^{45}$ (flexicurity ou flexiseguridad) - pauta importante na União Europeia -, abrangendo tanto a flexibilidade interna (mudanças na organização do trabalho, administração dos horários, modalidades das tarefas e evolução das responsabilidades, sistemas retributivos) quanto a flexibilidade externa (variações do número de funcionários, contratos atípicos e anormais, mobilidade). ${ }^{46}$

A globalização da economia, a relação entre as novas formas de trabalho e as tecnologias novas, a desestruturação do tempo e do espaço de trabalho, bem como a flexisegurança, vinculam-se com a evolução dos limites da duração do tempo de trabalho, pois possuem reflexos importantes em termos de duração do trabalho e demonstram (ainda que de maneira breve) as conexões que o tema possui, sua complexidade, dinamismo e constante evolução, que não se limita à evolução normativa (fontes formais), estando em constante produção de fontes materiais na prática das relações de trabalho.

42 FRIEDMAN, Thomas L. O mundo é plano: o mundo globalizado no século XXI. 3. ed. Rio de Janeiro: Objetiva, 2009, p. 66-69; Nesse sentido, no âmbito do direito do trabalho, ver: SUSSEKIND, Arnaldo. A globalização da economia e o Direito do Trabalho. Revista Ltr, São Paulo: Ltr, v. 61, p. 40, jan. 1997.

43 DE MASI, Domenico. O futuro do trabalho: fadiga e ócio na sociedade pós-industrial. 5. ed. Brasília: Unb, 2000, p. 222-227.

44 Uma das situações que refletem os novos contornos das relações econômicas e jurídicas advindas da pós-modernidade é o teletrabalho, também denominado trabalho por telecomunicação ou, em alemão, telearbeit, modalidade de trabalho que vem despertando o interesse do direito do trabalho de 1980 para cá (VILHENA, Paulo Emílio Ribeiro de. Relação de Emprego: estrutura legal e supostos. 2. ed. São Paulo: Ltr, 1999, p. 521). Segundo a Organização Internacional do Trabalho - OIT, o teletrabalho é qualquer trabalho realizado num lugar onde, longe dos escritórios ou oficinas centrais, o trabalhador não mantém um contato pessoal com seus colegas, mas pode comunicar-se com eles por meio das novas tecnologias (GBEZO, Bernard E. Otro modo de trabajar: la revolución del teletrabajo. Revista da OIT, n. 14, dez. 1995).

45 Para um estudo aprofundado sobre esse assunto, ver COIMBRA, Rodrigo; STURMER, Gilberto. A noção de trabalho a tempo parcial no direito espanhol como um instrumento da "flexisegurança". Direitos Fundamentais e Justiça, Porto Alegre: Hs Editora, n. 21, p. 39-57, out./dez. 2012.

46 Para um relato da busca da flexibilidade nos países europeus, separadamente, ver BAGLIONI, Guido. O mundo do trabalho: crise e mudança no final do século. São Paulo: Scritta, 1994. 


\subsection{No Brasil}

\subsubsection{Breve panorama até a Revolução de 1930}

No Brasil, as limitações do tempo trabalho, assim como o direito do trabalho como um todo, começaram efetivamente após a Revolução de 1930. Antes disso, mesmo no tempo do império, tivemos leis sociais sobre o trabalho, porém não era ainda "legislação social", mas apenas disposições legislativas fragmentárias. ${ }^{47}$

Cesarino Junior denomina o período de 1500 a 1888 como "pré-histórico", por nada haver a referir quanto ao direito do trabalho devido ao trabalho escravo. ${ }^{48}$ Segundo Evaristo de Moraes Filho, a chamada Lei Áurea de 1888 "significou, por si só, a primeira grande lei social entre nós, acabando com a escravidão e instituindo o regime do trabalho livre". ${ }^{49}$

A Constituição do Império (1824) limitou-se a assegurar a liberdade de trabalho no art. 179 e aboliu as corporações de ofício, influenciadas pela Revolução Francesa de 1789. 0 raro trabalho livre era regulado pelos Títulos 29 a 35 das Ordenações do Reino, artigos 226 e seguintes do Código Comercial e algumas leis especiais, como as de 13.9.1830, 11.10.1837 e 15.3.1789, sobre o contrato de prestação de serviços agrícolas..$^{50}$

0 primeiro período significativo na evolução do direito do trabalho no Brasil estende-se de 1888 a 1930, período em que a relação empregatícia se apresenta, de modo relevante, apenas no segmento cafeeiro avançado de São Paulo e, principalmente, na emergente industrialização experimentada na capital paulista e no Rio de Janeiro (nessa época, capital do país). ${ }^{51}$

Proclamada a República em 1889, a Constituição de 1981 limitou-se a dispor no artigo 72, o 24, sobre a liberdade do exercício de qualquer profissão moral, intelectual ou industrial, além do direito de associação e reunião ( $n$ - 8), e o ํo 29 do artigo 34 dispõe que legislar sobre "trabalho" é competência do congresso. Em que pese à parca previsão Constitucional, durante a Primeira República aparecem as primeiras leis trabalhistas. ${ }^{52}$

No direito pré-imperial e do Império do Brasil, nenhuma regra jurídica limitava a jornada de trabalho. A primeira lei, relativa aos trabalhos das crianças (Decreto no 1.313 de 1891), estabelece que os maiores de doze e menores de quinze

47 CESARINO JUNIOR, Antônio Ferreira; CARDONE, Marly A. Direito social. São Paulo: Ltr, 1993, p. 77.

48 CESARINO JUNIOR, Antônio Ferreira; CARDONE, Marly A. Direito social. São Paulo: Ltr, 1993, p. 77.

49 MORAES, Evaristo de. Apontamentos de direito operário. 4. ed. São Paulo: Ltr, 1998, p. 32 do prefácio escrito por Evaristo de Moraes Filho.

50 CESARINO JUNIOR, Antônio Ferreira; CARDONE, Marly A. Direito social. São Paulo: Ltr, 1993, p. 77.

51 DELGADO, Maurício Godinho. Curso de direito do trabalho. 5. ed. São Paulo: Ltr, 2006, p. 107.

52 CATHARINO, José Martins. Compêndio de direito do trabalho. 3. ed. São Paulo: Saraiva, 1982, p. 19. 
anos, do sexo feminino, somente poderiam trabalhar sete horas por dia, não consecutivas; e assim também os do sexo masculino, de doze a quatorze anos, sendo que os de quatorze a quinze, a duração diária máxima era de nove horas. ${ }^{53}$

Com o fim da Primeira Guerra Mundial em 1919 e com a assinatura do Tratado de Versalhes em 28.06.1919 (do qual o Brasil foi signatário), o Brasil entra numa nova fase de seu desenvolvimento social-trabalhista.

\subsubsection{A era Getúlio Vargas}

A era Getúlio Vargas não inaugura a legislação social no país, eis que, conforme acima noticiado, na República Velha foram editadas algumas normas esparsas de proteção ao trabalho, mas é a partir do momento em que Vargas assume o poder, em 1930, que o direito do trabalho passa a ser estruturado no Brasil. ${ }^{54}$

Após a instituição do Governo Provisório com a Revolução de 1930 (Decreto no 19.398 de 11.11.1930), Vargas criou, em 26.11.1930, o Ministério do Trabalho, Indústria e Comércio, ${ }^{55} \mathrm{com}$ as funções de elaboração, aplicação e fiscalização das leis trabalhistas. E em 16.11.1933, determinou a instalação de uma assembleia nacional constituinte.

Em 1932, foi estipulada a jornada de trabalho de oito horas para os trabalhadores do comércio e da indústria (Decretos no 21.186 e 21.364, respectivamente) e, a partir de então, para outras atividades, como barbearias, farmácias (seis horas), bancos (seis horas), transporte terrestres (oito horas), entre outras. ${ }^{56}$

Em 16.07.1934, encerrou-se o governo provisório com a promulgação da nova Constituição, prevendo uma série de direitos efetivamente trabalhistas, como: jornada de trabalho de oito horas e módulo semanal de 48 horas, salário mínimo, direta intervenção do Estado nas relações de trabalho, proibição de diferença de salário para trabalho igual, proibição de trabalho para menores de 14 anos, proibição de trabalho noturno para menores de 16 anos, proibição de trabaIho insalubre para mulheres e menores de 18 anos, indenização para despedida injusta, descanso à gestante após o parto, convenções coletivas, justiça do trabaIho, organização sindical/liberdade sindical (sob o regime de pluralidade sindical).

53 PONTES DE MIRANDA, Francisco Cavalcanti. Tratado de Direito Privado. t. 47. Campinas: Bookseller, 2006, p. 228.

54 Getúlio Dorneles Vargas "passaria para história como o Presidente que plantou as bases para o desenvolvimento industrial e elevou os trabalhadores à condição de sujeitos de direitos", de acordo com BIAVASCHI, Magda Barros. O direito do trabalho no Brasil - 1930 - 1942: a construção dos sujeitos de direitos trabaIhistas. São Paulo: Ltr, 2007, p. 111.

55 Lindolfo Collor foi o primeiro titular desse ministério.

56 MARTINS, Sérgio Pinto. Direito do Trabalho. 24. ed. São Paulo: Atlas, 2008, p. 477. 
Do golpe de Estado de 1937, emerge o chamado Estado Novo, sendo dissolvido o Congresso Nacional e outorgada, em 10.11.1937, uma nova Constituição, de cunho intervencionista e ditatorial, inspirada "pelo lado político, na Constituição Polonesa, e pelo lado econômico-social na Carta del Lavoro italiana, fascista, de 1927". ${ }^{57}$ Nesse contexto, foi mantida a jornada de trabalho de oito horas e o módulo semanal de 48 horas; contudo, o trabalho passou a ser encarado como dever social, sob a proteção do Estado (art. 136), e desapareceram os direitos sindicais e coletivos, a liberdade e a autonomia sindical, em troca de alguns direitos individuais. Passou-se para o regime de sindicato único (princípio da unicidade sindical, que permanece até os dias atuais), com a determinação do imposto sindical. A greve e o lockout foram considerados recursos antissociais. No âmbito infraconstitucional, no que toca às limitações da duração do trabalho, em 1937, foi estabelecida a jornada de sete horas para jornalistas e determinado o máximo de seis aulas intercaladas para os professores. ${ }^{58}$

Em 1942, o Ministério do Trabalho nomeou comissão para elaborar uma Consolidação, sendo seu trabalho convertido no Decreto-Lei no 5.452, de 01.05.1943: Consolidação das Leis do Trabalho. No que diz respeito à duração do trabalho, a Consolidação ${ }^{59}$ incorporou os decretos esparsos e estabeleceu a regra geral de jornada de oito horas. Esta matéria está prevista no Capítulo II - “Da Duração do Trabalho" (artigos 57 a 75), divido em “jornada de trabalho”, "períodos de descanso (contemplado normas sobre intervalos intra(dentro) e inter(entre)jornadas, comuns e especiais), "trabalho noturno", "quadro de horário", "penalidades".

\subsubsection{A experiência legislativa após a era Vargas}

Com o fim da ditadura do Estado Novo, foi promulgada a nova Constituição Federal, em 18.09.1946, de cunho socialdemocrata, na linha da Constituição de 1934, aproveitando-se das conquistas do pós-Segunda Guerra Mundial.

As Constituições Federais de 1946 e de 1967 (bem como a Emenda Constitucional no 1/69) mantiveram a jornada de trabalho em oito horas e o módulo semanal em 48 horas. Entre 1946 e 1967 (nova Constituição), foram criados e/ou regulamentados importantes direitos trabalhistas por meio de leis esparsas,

MORAES, Evaristo de. Apontamentos de direito operário. 4. ed. São Paulo: Ltr, 1998, p. 109.

58 MARTINS, Sérgio Pinto. Direito do Trabalho. 24. ed. São Paulo: Atlas, 2008, p. 477.

59 Em termos de estrutura e conteúdo, a Consolidação não é uma coleção de leis, mas a sua coordenação sistematizada: "Não é apenas um engenho de arquitetura legislativa, mas uma recapitulação de valores coerentes, que resultaram de uma grande expansão legislativa, anterior, em um dado ramo do direito" (Item 11 da exposição de motivos da CLT, CLT-LTR 2008, p. 29). 
como a Lei $\mathrm{n}^{\circ}$ 605, de 05.01.1949, que detalhou sobre o repouso semanal remunerado ${ }^{60}$ e os feriados civis e religiosos, não obstante o disposto sobre a matéria nos artigos 68 a 70 da CLT. Só a lei poderia decretar feriados. ${ }^{61}$

A partir do Golpe Militar de 1964, a evolução do direito do trabalho foi "refreada, em benefício de medidas de economia pura, notadamente financeiras, com vistas a resultados de curto prazo". ${ }^{62}$ Merece destaque, em face das profundas consequências para o direito do trabalho brasileiro, a criação do Fundo de Garantia por Tempo de Serviço - FGTS pela Lei no 5.107, de 13.09.1966. ${ }^{63}$

Em 24.01.1967, foi promulgada uma nova Constituição, alterada pela Emenda Constitucional no 1 de 17.10.1969, consagrando a ditadura militar no Brasil, que iria durar até 1984. Essa nova Constituição introduziu novas matérias, dentre as quais se destaca a proibição de greve em serviços públicos e atividades essenciais (art. 157). ${ }^{64}$

Em 13.04.1977, por meio do Decreto-Lei № 1.535, foi alterado o Capítulo IV do Título II da CLT, no que tange às férias anuais, passando a ser de 30 dias corridos, a cada 12 meses de trabalho, para quem tiver até cinco faltas injustificadas em cada período de 12 meses (art. 130 da CLT).

A partir do início de 1985, inicia-se o “lento e gradual” processo de redemocratização do país. Continuava em vigor a Constituição de 1967, mas, aos poucos, o direito do trabalho foi retomando o seu rumo iniciado em 1930 e sucessivamente restringido, destacando-se, no ordenamento infraconstitucional trabalhista, o Decreto-Lei no 2.284, de 10.03.1986, que institui o direito ao seguro-desemprego

60 O repouso semanal remunerado contemplado posteriormente pela Constituição Federal de 1988 (art. 7으, $\mathrm{XV}$ ) deve ser concedido aos domingos, em regra geral, mas a legislação esparsa contempla exceções. Se for concedido após o sétimo dia consecutivo de trabalho, gera direito ao seu pagamento em dobro, de acordo com a Orientação Jurisprudencial no 410 da SDI-1 do TST.

61 PONTES DE MIRANDA, Francisco Cavalcanti. Tratado de Direito Privado. t. 47. Campinas: Bookseller, 2006, p. 236.

62 CATHARINO, José Martins. Compêndio de direito do trabalho. 3. ed. São Paulo: Saraiva, 1982, p. 28.

63 Em face dessas normas, o empregado tinha que "optar", podendo fazer isso inclusive retroativamente, pelo sistema do FGTS. O que não se deixava claro aos empregados é que esse novo direito estava sendo trocado pelo maior direito do trabalhador: a estabilidade definitiva, conquistada após 10 anos de serviço para o mesmo empregador (por isso chamada de “decenal”). A CF de 1988 (art. 7ํㅡ, III) pôs fim à opção do FGTS, passando a ser um direito obrigatório e irrenunciável por parte do trabalhador. Passa a ser devido também aos empregados rurais a partir de 05.10.88. A Lei oㅜ 8.036, de 11.05.90, versou sobre o FGTS, revogando expressamente a Lei no 7.839 (art. 32). Foi regulamentada pelo Decreto no 99.684, de 08.11.90. Essas são as atuais disposições sobre o FGTS.

64 Da legislação infraconstitucional da época, merece referência especial a Lei no 5.584, de 16.06.1970, dispondo sobre diversas questões processuais trabalhistas utilizadas ainda hoje, como os requisitos para percepção dos honorários assistenciais na Justiça do Trabalho, o rito de alçada ou sumário, entre outras questões; a Lei Complementar no 7, de 07.09.1970 e Decreto-Lei no 1.125, de 19.09.1970, que criou o PIS - Programa de Integração Social; a Lei no 6.019, de 03.01.1974, disciplinando o trabalho temporário. 
com a finalidade de prover assistência financeira temporária ao trabalhador desempregado, sucessivamente regulamentado posteriormente. A Lei oㅜ 7.619, de 30.09.1987, ${ }^{65}$ criou o vale-transporte.

Em 05.10.1988, é promulgada a atual Constituição Federal, estabelecendo, dentro dos direitos e garantias fundamentais, direitos sociais amplos (sendo o trabalho contemplado entre direitos sociais previstos no art. 6ํ) e um significativo rol não taxativo de direitos para os trabalhadores urbanos e rurais previstos no art. 7을 dentre os quais, no que concerne especialmente à duração do trabalho, se destaca que a Constituição Federal de 1988, não obstante tenha mantido a jornada de trabalho em oito horas, inovou ao reduzir o módulo semanal para 44 horas, facultadas a compensação de horários e a redução da jornada, mediante acordo ou convenção coletiva de trabalho (inciso XIII), e ao introduzir jornada de seis horas para o trabalho realizado em turnos ininterruptos de revezamento, salvo negociação coletiva (inciso XIV).

Trata-se de limites legais máximos, ou seja, nada impede que, por lei especial, disposição contratual, regulamentar ou por normas coletivas, seja fixada jornada de trabalho inferior a oito horas diárias e 44 semanais. Nesse caso, valerá essa norma mais favorável ou condição mais favorável ao empregado, tal como estipulada. ${ }^{66}$

O inciso XIV do art. 7ํ da Constituição Federal de 1988 é uma das hipóteses de limite inferior. Conforme esclarece Stürmer: 67

Entendeu o constituinte que esta situação resulta em prejuízo biológico e social para ao empregado. É que, submetido a escala de turnos ininterruptos de revezamento o empregado desorganiza o seu período de repouso e de outras atividades pessoais, sociais e familiares, o que de fato ocorre.

A Constituição Federal de 1988 é que trouxe no seu bojo a maior amplitude de direitos sociais trabalhistas, sinalizando a importância reconhecida aos direitos trabalhistas para o Brasil. Trata-se da intervenção indireta do Estado na economia visando, entre outros objetivos, melhorar a distribuição de renda e coibir os abusos por parte do empregador. Além disso, as normas trabalhistas também visam

65 Art. 1ำ Fica instituído o vale-transporte, que o empregador, pessoa física ou jurídica, antecipará ao empregado para utilização efetiva em despesas de deslocamento residência-trabalho e vice-versa, através do sistema de transporte coletivo público, urbano ou intermunicipal e/ou interestadual com características semelhantes aos urbanos, geridos diretamente ou mediante concessão ou permissão de linhas regulares e com tarifas fixadas pela autoridade competente, excluídos os serviços seletivos e os especiais.

66 Nesse sentido: STURMER, Gilberto. Direito Constitucional do Trabalho no Brasil. São Paulo: Atlas, 2014, p. 48.

67 STURMER, Gilberto. Direito Constitucional do Trabalho no Brasil. São Paulo: Atlas, 2014, p. 52. 
melhorar as condições de trabalho e a saúde dos trabalhadores. Podem, também, ser vistas desde a perspectiva das empresas, que teriam maior previsibilidade das condutas e mais segurança nas relações jurídicas, além do fato de que as normas trabalhistas também exercem homogeneizar a concorrência. Tudo isso converge para o objetivo maior de evitar os conflitos sociais e colaborar para a paz social. ${ }^{68}$

A Constituição atual inovou, ainda, ao aumentar o adicional de horas extras para no mínimo 50\% sobre o valor da hora normal trabalho (inciso XV), pois, até então, o adicional era de pelo menos $20 \%,{ }^{69}$ conforme o disposto no $\S 11^{\circ}$ do art. 59 da CLT. Outra inovação marcante da Constituição de 1988 foi o acréscimo do valor da remuneração das férias em pelo menos um terço a mais do salário normal trabalho (inciso XVII do art. 7으), por isso chamado por alguns de "terço constitucional de férias". Cabe, por fim, salientar a preocupação do legislador constituinte de 1988 de que o repouso semanal remunerado seja preferencialmente aos domingos (inciso XV do art. $7^{\circ}$ ).

Cabe registrar que a existência da Proposta de Emenda Constitucional - PEC no 231/95, apresentada pelo Deputado Inácio Arruda PCdoB/CE, que tramita na Câmara dos Deputados, visando diminuir o módulo semanal de trabalho de 44 para 40 horas, sem redução de salário, bem como aumentar o valor do adicional de hora extra de no mínimo 50\% para no mínimo 75\% sobre a hora normal. O doutrinador e ministro do Tribunal Superior do Trabalho Maurício Godinho Delgado ${ }^{70}$ apoia essa ideia destacando que "a diminuição para 40 horas do módulo semanal de labor no Direito brasileiro constitui notável medida de saúde no ambiente do trabalho, por restringir o desgaste inerente à atividade laborativa, com a fundamental ênfase de que se trata, regra geral, de redução apta a propiciar o franqueamento de um inteiro dia adicional, dentro da semana, para o respectivo trabalhador brasileiro", constituindo "medida central no processo indispensável de incremento do mercado econômico interno do país".

Em 5.10.1999, por meio do Decreto $\mathrm{n}$ - 3.197, o Brasil promulgou a Convenção no 132 da Organização Internacional do Trabalho sobre férias anuais remuneradas, revista em Genebra em 1970. ${ }^{71}$

COIMBRA, Rodrigo; ARAÚJO, Francisco Rossal de. Direito do Trabalho I. São Paulo: Ltr, 2014, p. 139-140.

69 Nesse sentido: STURMER, Gilberto. Direito Constitucional do Trabalho no Brasil. São Paulo: Atlas, 2014, p. 55.

70 DELGADO, Maurício Godinho. Duração do Trabalho - o debate sobre a redução para 40 horas semanais. Revista do Tribunal Superior do Trabalho, Brasília, v. 75, n. 2, p. 25-34, em especial p. 26-27 e 31, abr./ jun. 2009.

71 Para um estudo detalhado da Convenção nํ 132 da Organização Internacional do Trabalho, ver COUTINHO, Aldacy Rachid. As férias depois da Convenção 132 da OIT. Revista do Tribunal Regional do Trabalho da 9a Região, Curitiba, n. 48, p. 13, jul./dez. 2002. 
A Lei no 11.603, de 05.12.2007 inseriu o art. 6--A na Lei no 10.101/2000, permitindo o trabalho, no comércio em geral, aos domingos, observada a legislação municipal, nos termos do art. 30, inciso I, da Constituição. 0 repouso semanal remunerado deverá coincidir, pelo menos uma vez no período máximo de três semanas, com o domingo, respeitadas as demais normas de proteção ao trabalho e outras a serem estipuladas em negociação coletiva. ${ }^{72} \mathrm{Em}$ trabalho específico, Mallet ${ }^{73}$ manifesta entendimento de que a autorização em convenção coletiva não é imprescindível para o desenvolvimento lícito de trabalho em feriados no comércio em geral. Sustenta que, editada disposição geral, não ficaram prejudicadas as disposições especiais anteriores, como as atividades favorecidas pelo Decreto no 27.048/49 (que regulamenta a Lei no 605/49), como nos casos dos supermercados voltados ao comércio varejista; assim, tais atividades poderão continuar a funcionar em feriados independentemente de celebração de convenção coletiva de trabalho.

A Lei $n \cong 12.551$, de 15.12.2011, alterou o art. 6으 da CLT para equiparar os efeitos jurídicos da subordinação exercida por meios telemáticos e informatizados à exercida por meios pessoais e diretos, tutelando nesse particular o chamado "teletrabalho", dispondo que "não se distingue entre o trabalho realizado no estabelecimento do empregador, o executado no domicílio do empregado e o realizado a distância, desde que estejam caracterizados os pressupostos da relação de emprego. Parágrafo único. Os meios telemáticos e informatizados de comando, controle e supervisão se equiparam, para fins de subordinação jurídica, aos meios pessoais e diretos de comando, controle e supervisão do trabalho alheio". Esse dispositivo gera uma série de reflexões sobre o controle da duração do trabalho do empregador sobre o "teletrabalhador", matéria ainda inquietante e cujo aprofundamento não é objeto do presente trabalho.

Em 02.04.2013, foi promulgada a Emenda Constitucional № 72, que altera o parágrafo único da Constituição Federal para estabelecer a igualdade de direitos trabalhistas entre os trabalhadores domésticos e os demais trabalhadores urbanos e rurais. A partir de então, os empregados domésticos, no que tange à duração do trabalho, também passam a ter direito à jornada de trabalho de oito horas e do módulo semanal de 44 horas, pagamento de adicional de hora extra de no mínimo 50\%, entre outros direitos. É importante dizer que esse novo direito teve vigência imediata, diferentemente de outros atribuídos aos trabalhadores domésticos pela Emenda Constitucional no 72 que ficaram pendentes de regulamentação (como o FGTS, por exemplo).

72 Art. 6-A e B, da Lei no 10.101/2000.

73 MALLET, Estevão. Prática de Direito do Trabalho. v. 2. São Paulo; Ltr, 2012, p. 120-124. 
Essa matéria, em face de sua dinâmica e importância, estará e precisa ser objeto de constantes acréscimos e alterações no âmbito legislativo, sobretudo no que tange à necessidade de tratamento diferenciado para alguns tipos de trabalhadores, cuja natureza do trabalho exige limites de duração do trabalho adequados às suas diferenças.

A Constituição Federal estipula limites gerais, e a Consolidação das Leis do Trabalho dispõe de modo diferenciado no capítulo da tutela especial de trabalho; todavia, de 1943 para cá, surgiram muitas novas formas de trabalho que não possuem tratamento jurídico adequado em termos de duração de trabalho, dentre as quais se destaca, por exemplo, o trabalho desempenhado no âmbito da chamada tecnologia da informação.

O direito do trabalho pátrio precisa construir essa atualização, tendo sempre em mente os princípios que o inspiram.

\section{Considerações finais}

A duração do trabalho foi e continua sendo um dos temas mais importantes do direito do trabalho, pois a necessidade de se estabelecer limites imperativos ao tempo dedicado ao trabalho (diário, semanal, mensal e anual) segue sendo uma complexa e difícil questão, haja vista sua dinâmica e a constante modificação nas formas de trabalho notadamente num contexto de globalização da economia e da chamada revolução tecnológica.

Essa temática insere-se no âmbito das limitações constitucionais ao exercício da atividade econômica como manifesta intervenção do Estado na economia e nas relações de trabalho, visando nivelar a desigualdade econômica existente entre empregados e empregadores por meio de limites mínimos e máximos estabelecidos pela legislação (princípio da proteção do empregado).

Os fundamentos jurídicos da duração do tempo de trabalho no Brasil analisados e sistematizados no presente texto continuam adequados e inspiram limites necessários. O que se pode e deve constantemente debater, pelo dinamismo que circunda a matéria (evidenciado no estudo da evolução histórica), diz respeito à melhor adequação dos limites de duração do tempo de trabalho tendo em vista os contextos de cada sociedade e época, tendo sempre em mente os princípios que o inspiram.

A limitação jurídica da duração do tempo de trabalho segue motivada pelos aspectos de natureza física ou biológica, psíquica e psicológica, social e cultural, bem como econômica, cujos limites maiores, em última análise, são a vida, a saúde e a dignidade da pessoa humana dos trabalhadores. 
O estudo dos fundamentos e da evolução dos limites da duração do trabalho no direito internacional e no Brasil é necessário para que se possa compreender o presente e projetar o futuro, tendo em mente o objetivo histórico e sempre atual do direito do trabalho de conciliar o capital e o trabalho, procurando equilibrar o desenvolvimento do alcance dos resultados esperados pelos empreendimentos econômicos empresariais com a elevação da dignidade humana do trabalhador.

No que tange à constante necessidade de melhor adequação dos limites de duração do tempo de trabalho, é imprescindivel que se dê mais atenção às exigências sociais de regulamentação diferenciada dos limites de duração do trabalho para alguns tipos de trabalhadores, cuja natureza do trabalho exige limites de duração do trabalho adequados às suas diferenças, seja por meio de negociação coletiva, sempre que possível, seja por meio da legislação, quando a intervenção do Estado se mostrar necessária, ou muitas vezes através das duas formas combinadas.

Uma medida concreta seria a legislação impedir a realização de horas extras, como regra geral, admitindo-se apenas em situações excepcionais, como de força maior (já prevista na CLT).

De nada adianta, por exemplo, reduzir a carga horária semanal de 44 para 40 horas e continuar permitindo a prática da realização de horas extras habituais, o que, além de um grande contrassenso (pois, como diz seu nome completo, são horas "extraordinárias" e, como tais, não poderiam ser praticadas com habitualidade), prejudica a realização das demais atividades que integram a vida do trabalhador.

No contexto de desestruturação do tempo e do espaço de trabalho em que vivemos, têm surgido várias situações novas, dentre as quais se destacam muitas mudanças envolvendo organização do trabalho, administração dos horários, modalidades das tarefas e evolução das responsabilidades, sistemas retributivos, contratos atípicos, mobilidade, entre outras questões que influem de forma significativa na regulação dos limites de duração do trabalho, constituindo-se alguns dos grandes desafios atuais do direito do trabalho.

Recebido em: 04.01.2016.

Pareceres: 29.03.2016 e 22.08.2016.

Aprovado em: 13.12.2016.

Abstract: This article deals with one of the most important themes of Labor Law from its historical formation to its inclusion in the Brazilian Constitutions: the limitation of working time (daily, weekly, monthly and annual). The problems investigated in the research are the following: are the fundamentals 
and legal limits of working time in Brazil still necessary and adequate? It is argued that the legal foundations of working time in Brazil remain adequate and inspire necessary limits, motivated by aspects of physical, biological, psychological and psychological, social and cultural, as well as economic, whose ultimate limits are ultimately Life, health and dignity of the human person of the workers. As a scientific method of approach the subject will be used the deductive method and approach of the research will be given by the qualitative model.

Keywords: Duration of work. Historical evolution. Fundamentals. Fundamental rights. Human rights.

Summary: $\mathbf{1}$ Introduction - $\mathbf{2}$ Fundamentals of length of working time - $\mathbf{3}$ Historical evolution of the limits of working time $\mathbf{- 4}$ Final considerations - References

\section{Referências}

ARAÚJO, Francisco Rossal de. A saúde do trabalhador como direito fundamental (no Brasil). Justiça do Trabalho, Porto Alegre: Hs Editora, n. 317, p. 7-32, maio 2010.

BAGLIONI, Guido. O mundo do trabalho: crise e mudança no final do século. São Paulo: Scritta, 1994.

BARBAGELATA, Héctor-Hugo. A evolução do pensamento do direito do trabalho. São Paulo: Ltr, 2012.

BARROS, Alice Monteiro de. Curso de Direito do Trabalho. 4. ed. São Paulo: Ltr, 2008.

BIAVASCHI, Magda Barros. O direito do trabalho no Brasil - 1930 - 1942: a construção dos sujeitos de direitos trabalhistas. São Paulo: Ltr, 2007.

CATHARINO, José Martins. Compêndio de direito do trabalho. 3. ed. São Paulo: Saraiva, 1982.

CESARINO JÚNIOR, Antônio Ferreira; CARDONE, Marly Antonieta. Direito Social: teoria geral do direito social, direito contratual do trabalho, direito protecionista do trabalho. 2. ed. São Paulo: Ltr, 1993.

COIMBRA, Rodrigo. Globalização e internacionalização dos direitos fundamentais dos trabalhadores. Revista de Direito do Trabalho, São Paulo: Revista dos Tribunais, n. 146, p. 411-431, abr./jun. 2012.

COIMBRA, Rodrigo; ARAúJO, Francisco Rossal de. Direito do Trabalho I. São Paulo: Ltr, 2014, p. 140.

COIMBRA, Rodrigo; ARAÚJO, Francisco Rossal de. Direito do Trabalho: evolução do modelo normativo e tendências atuais na Europa. Revista Ltr, São Paulo, ano 73, t. II, n. 08, p. 960, ago. 2009.

COIMBRA, Rodrigo; ARAÚJO, Francisco Rossal de. Equilíbrio instável das fontes formais do Direito do Trabalho. Justiça do Trabalho, v. 324, p. 48-75, dez. 2010.

COIMBRA, Rodrigo; STURMER, Gilberto. A noção de trabalho a tempo parcial no Direito Espanhol como um instrumento da "flexisegurança". Direitos Fundamentais e Justiça, Porto Alegre: Hs Editora, n. 21, p. 39-57, out./dez. 2012. 
COUTINHO, Aldacy Rachid. As férias depois da Convenção 132 da OIT. Revista do Tribunal Regional do Trabalho da 9a Região, Curitiba, n. 48, p. 13, jul./dez. 2002.

D’EUFEMIA, Giuseppe. Diritto del lavoro. Napoli: Morano, 1969.

DE LA CUEVA, Mario. El nuevo Derecho Mexicano del Trabajo. t. 1. 19. ed. México: Porrúa, 2003.

DE MASI, Domenico. O futuro do trabalho: fadiga e ócio na sociedade pós-industrial. 5. ed. Brasília: Unb, 2000.

DELGADO, Maurício Godinho. Duração do Trabalho - o debate sobrea redução para 40 horas semanais. Revista do Tribunal Superior do Trabalho, Brasília, v. 75, n. 2, p. 25-34, abr./ jun. 2009.

DELGADO, Maurício Godinho. Curso de Direito do Trabalho. 10. ed. São Paulo: Ltr, 2011.

DELGADO, Maurício Godinho; DELGADO, Gabriela Neves. O princípio da dignidade da pessoa humana e o Direito do Trabalho. In: SARLET, Ingo Wolfgang; MELO FELICIANO, Guilherme Guimarães. Diálogos entre o Direito Trabalho e o Direito Constitucional: estudos em homenagem a Rosa Maria Weber. Curso crítico de Direito do Trabalho: Teoria Geral do Direito do Trabalho. São Paulo: Saraiva, 2013.

FRIEDMAN, Thomas L. O mundo é plano: o mundo globalizado no século XXI. 3. ed. Rio de Janeiro: Objetiva, 2009.

GARCIA, Gustavo Filipe Barbosa. Manual de Direito do Trabalho. 5. ed. São Paulo: Método, 2012. GBEZO, Bernard E. Otro modo de trabajar. la revolución del teletrabajo. Revista da OIT, n. 14, dez. 1995.

GOMES, Orlando; GOTTSCHALK, Élson. Curso de Direito do Trabalho. 18. ed. Rio de Janeiro: Forense, 2007.

HEPLE, Bob. La formación del Derecho del Trabajo en Europa. Madrid: Ministerio de Trabajo y Seguridad Social, 1994.

HUECK, A.; NIPPERDEY, H. C. Compendio de derecho del trabajo. Madrid: Revista de Direito Privado, 1963.

LEÃO XIII. Carta encíclica "Rerum Novarum" sobre a condição dos operários. Disponível em: <http://www.vatican.va/holy_father/leo_xiii/encyclicals/documents/hf_l-xiii_ enc_15051891_rerum-novarum_po.html>. Acesso em: 10 abr. 2013.

LEE, Sangheon. Duração do trabalho em todo o mundo: tendências de jornadas de trabalho, legislação e políticas numa perspectiva global comparada. Brasília: OIT, 2009.

MALLET, Estevão. Prática de Direito do Trabalho. v. 2. São Paulo: Ltr, 2012.

MAIOR, Jorge Luiz. Do direito à desconexão do trabalho. Justiça do Trabalho, Porto Alegre: Hs Editora, n. 238, p. 7-22, out. 2003.

MARANHÃO, Délio. Direito do Trabalho. 14. ed. Rio de Janeiro: Fundação Getúlio Vargas, 1987.

MARTINS, Sérgio Pinto. Direito do Trabalho. 24. ed. São Paulo: Atlas, 2008.

MARTINS, Sérgio Pinto. Convenções da OIT. São Paulo: Atlas, 2009. 
MARX, Karl. Manifesto do Partido Comunista. Porto Alegre: L\&PM, 2001.

MELLO, Marcos Bernardes de. Teoria do fato jurídico: plano da existência. 8. ed. São Paulo: Saraiva, 1998.

MORAES FILHO, Evaristo de; MORAES, Antônio Carlos Flores de. Introdução ao Direito do Trabalho. 7. ed. São Paulo: Ltr, 1995.

MORAES, Evaristo de. Apontamentos de direito operário. 4. ed. São Paulo: Ltr, 1998.

NASCIMENTO, Amauri Mascaro. Iniciação ao Direito do Trabalho. 24. ed. São Paulo: Ltr, 1998.

NASCIMENTO, Amauri Mascaro. Direito contemporâneo do trabalho. São Paulo: Ltr, 2011.

OLEA, Manuel Alonso. Introdução ao Direito do Trabalho. 4. ed. São Paulo: Ltr, 1984.

PONTES DE MIRANDA, Francisco Cavalcanti. Tratado de Direito Privado. t. 47. Campinas: Bookseller, 2006.

RUSSOMANO, Mozart Victor. Curso de Direito do Trabalho. 4. ed. Curitiba: Juruá, 1993.

SANTOS, Boaventura de Souza. Os processos de globalização. In: SANTOS, Boaventura de Souza (Org.). A globalização e as ciências sociais. 3. ed. São Paulo: Cortez, 2005.

SARLET, Ingo Wolfgang. Direitos fundamentais e processo: o direito à proteção e promoção da saúde entre tutela individual e transindividual. Revista de Processo, São Paulo, v. 199, p. 13-39, set. 2011.

SUSSEKIND, Arnaldo. A globalização da economia e o Direito do Trabalho. Revista Ltr, São Paulo: Ltr, v. 61, p. 40-44, jan. 1997.

SUSSEKIND, Arnaldo et al. Instituições de Direito do Trabalho. v. 2. 20. ed. São Paulo: Ltr, 2002.

STURMER, Gilberto. Direito Constitucional do Trabalho no Brasil. São Paulo: Atlas, 2014.

STURMER, Gilberto; COIMBRA, Rodrigo. A noção de trabalho a tempo parcial no Direito Espanhol como um instrumento da "flexisegurança". Direitos Fundamentais e Justiça, Porto Alegre: Hs Editora, n. 21, p. 39-57, out./dez. 2012.

TUCCI, José Rogério Cruz e. Tempo e processo: uma análise empírica das repercussões no tempo na fenomenologia processual (civil e penal). São Paulo: Revista dos Tribunais, 1997.

VILHENA, Paulo Emílio Ribeiro de. Relação de Emprego: estrutura legal e supostos. 2. ed. São Paulo: Ltr, 1999.

Informação bibliográfica deste texto, conforme a NBR 6023:2002 da Associação Brasileira de Normas Técnicas (ABNT):

COIMBRA, Rodrigo. Fundamentos e evolução da limitação constitucional da duração do tempo de trabalho no Brasil. Direitos Fundamentais \& Justiça, Belo Horizonte, ano 10, n. 35, p. 149-170, jul./dez. 2016. 